\title{
TECNOLOGIAS MÓVEIS NOS PROCESSOS DE ENSINO E DE APRENDIZAGEM: MOBILIDADE DOCENTE?
}

\author{
Osmar Hélio Alves ARAÚJO ${ }^{1}$ \\ Luis Tavora Furtado RIBEIRO ${ }^{2}$ \\ Maria Nerice dos Santos PINHEIRO ${ }^{3}$
}

RESUMO: O artigo trata de uma pesquisa realizada junto a professores da educação básica do município de Iguatu/CE e teve como objetivo verificar se os professores utilizam as tecnologias móveis em sala de aula como recurso pedagógico, assim como investigar em que medida a qualificação profissional dos referidos profissionais impulsiona uma ação docente autêntica, autônoma diante da seara das tecnologias móveis. Os sujeitos são professores que atuam no Ensino Fundamental. Metodologicamente, constitui-se em uma pesquisa de campo, com arrimo na abordagem qualitativa, visando realçar que a escola na contemporaneidade é interpelada pelas transformações trazidas à sociedade pela revolução tecnológica, mormente pela proliferação das tecnologias móveis, as quais estão a impulsionar mudanças nos processos de ensino e de aprendizagem. Utilizou-se da entrevista semiestruturada e reflexiva como técnica para a coleta de dados. Têm como aporte teórico os estudos de Alarcão (2001), Freire (1987, 1992, 2001), Libâneo (2001, 2002, 2005, 2011), Nóvoa (2009), Tardif (2013) UNESCO (2013), Veen e Vrakking (2009). Os resultados da pesquisam evidenciaram que os professores, na sua grande maioria, não utilizam a aparelhagem das tecnologias móveis na prática pedagógica, assim como apontam para o quadro da qualificação profissional insuficiente para uma atuação docente no contexto das tecnologias de modo seguro e pedagogicamente eficaz. No entanto, tal cisão desemboca, portanto, na necessidade de um processo de formação contínua que se aprofunde, também, na realidade e nos conhecimentos que os professores possuem. Assim como considerar como pilares as mudanças que o contexto social vigente vem passando, entre as quais se destacam as transformações tecnológicas que se proliferam vertiginosamente.

PALAVRAS-CHAVE: Tecnologias móveis. Ensino e aprendizagem. Formação docente.

\section{INTRODUÇÃO}

Dada à proliferação da aparelhagem tecnológica, mais precisamente das tecnologias móveis no contexto social vigente, século XXI, é preciso considerar,

\footnotetext{
${ }^{1}$ Professor-formador. PARFOR - Plano Nacional de Formação de Professores da Educação Básica, junto à Universidade Estadual Vale do Acaraú-UVA. Sobral - CE - Brasil. 62.040-370. Docente colaborador. Pós-Graduação Lato Sensu das Faculdades INTA. Sobral - CE - Brasil. 62050-100 osmarhelio@hotmail.com

${ }^{2}$ Professor associado. UFC - Universidade Federal do Ceará. Faculdade de Educação. Fortaleza - CE Brasil. 60020-060. Pós-doutorado. EHESS - École de Hautes Études en Sciences Sociales, sob a supervisão de Michel Löwy. Paris - França. 75013 - luistavora@uol.com.br

3 Mestranda em Educação. UFC - Universidade Federal do Ceará. Faculdade de Educação - PósGraduação em Educação. Fortaleza - CE - Brasil. 60020-060 - nematu@ gmail.com.
} 
portanto, que o contexto escolar não pode ficar alheio à cultura tecnológica. Toda a aparelhagem tecnológica tem penetrado nos diferentes estrados da sociedade, com implicações cada vez mais diretas sobre os sujeitos e suas respectivas relações. A difusão de informações, entretenimento e conectividade oferecem uma cultura de proximidade entre os sujeitos, facilitando os percursos da mobilidade para o processo de aprendizagem.

Neste contexto de influência das tecnologias de informação e comunicação sobre os sujeitos na contemporaneidade, a escola precisa, por um lado, estabelecer um diálogo com a aparelhagem tecnológica, assim como oportunizar aos professores um processo de formação que fomente a inserção dos referidos aparatos na prática pedagógica. Deste modo, a escola precisa instigar os professores a penetrarem no contexto das tecnológicas móveis, visto que a população discente está, cada vez mais, sendo intimada à cultura midiática. Nesta perspectiva, faz-se oportuno trazer para o debate os resultados da pesquisa realizada com professores de escolas públicas municipais de Iguatu/CE. A ação investigativa foi dirigida pelo intento de averiguar se os professores utilizam as tecnologias móveis em sala de aula como recurso pedagógico, bem como investigar em que medida a qualificação profissional dos referidos profissionais impulsiona uma ação docente autêntica, autônoma e pedagogicamente eficaz diante da realidade das tecnologias móveis.

O objetivo desta reflexão é contribuir com o debate sobre as tecnologias móveis nos processos de ensino e de aprendizagem, trazendo à baila o diálogo materializado com os professores por meio de entrevista, visando, assim, descortinar possibilidades do uso dos instrumentos tecnológicos móveis na prática pedagógica e no cotidiano da sala de aula. Parte-se da compreensão de que é recomendável um liame entre a cultura escolar e o campo tecnológico. Entretanto, os resultados da pesquisa apontam que os professores não utilizam, de fato, a aparelhagem das tecnologias móveis como recursos pedagógicos. Logo, tal quadro é justificado pelos docentes, ao apontarem a insuficiente qualificação profissional que não os permitem uma atuação em interface a esse contexto de modo seguro e profícuo.

Assim, espera-se que a discussão apresente contributos para o debate a respeito da questão em tela, pois a inserção das tecnologias móveis nos processos de ensino e de aprendizagem, a partir de novos olhares ancorados nas assertivas dos professores, sugere a necessidade de uma premente formação para o docente que instigue práticas com aporte na referida relação, tecnologias móveis e a prática pedagógica. Esta 
experiência urge ser erguida visando, sobretudo, medrar a qualificação dos professores para um labor seguro no contexto das tecnologias móveis. Afinal, as tecnologias móveis são aliadas ou inimigas dos processos de ensino e de aprendizagem?

\section{CONTRIBUIÇÕES TEÓRICAS PARA O ENTENDIMENTO DA QUESTÃO EM TELA}

As Tecnologias de Informação e Comunicação, também popularmente conhecidas como TIC's, vem se instaurando de forma relevante no âmbito educacional. Além disso, se reconfiguram com grande velocidade, ganhando novos formatos e usos. Contudo, nem sempre foi assim, e na verdade o seu significado para a educação tornouse mais pujante a partir da década 1990, século XX, por meio da socialização de um discurso cada vez mais modernizante e informacional. Nesse mesmo caminho, Nóvoa (2009, p. 64, grifo nosso) adverte que:

\footnotetext{
Um dos grandes perigos dos tempos atuais é uma "escola a duas velocidades": por um lado, uma escola concebida essencialmente como um centro de acolhimento social, para os pobres, com uma forte retórica da cidadania e da participação; por outro lado, uma escola claramente centrada na aprendizagem, e nas tecnologias, destinada a formar os filhos dos ricos.
}

Verifica-se, portanto, que, no decurso do século em voga, século XXI, a relação do processo de aprendizagem e as tecnologias estão tornando-se cada vez mais desafiadoras. Entretanto, o autor realça o mote desencadeando por tal situação, em outras palavras, com o passar do tempo os processos de ensino e de aprendizagem correlatos ao uso das novas tecnologias tem se tornado patente em diferentes escolas, $\mathrm{o}$ que toca a tangente do ensino e aprendizagem em simbiose com a arena tecnológica. Todavia, nessa estrutura, Alarcão (2001) enfatiza que a escola precisa elidir seus modelos estáticos, destemperados e atuar dinamicamente em consonância com as sinergias provenientes das interações com o contexto social. Por isso, assenta-se o intento desta pesquisa em sustentar a necessária inserção das tecnologias móveis nos processos de ensino-aprendizagem.

Alguns estudiosos definem a sociedade contemporânea como a era da aprendizagem ou do conhecimento, entre eles Sibilia (2012). Isso ocorre em decorrência da intensificação e da velocidade das informações que se materializam com base no uso das TIC's, enquanto instrumentos de socialização do saber. Nesta toada, com esteio nos 
estudos de Libâneo (2001), leva-se a cabo que as inusitadas tecnologias da comunicação e da informação, provocaram mudanças nos moldes tradicionais correlatos aos processos de ensino e de aprendizagem. Todavia, a informação é uma via de acesso ao conhecimento, porém, por si só, não tem forma motriz para fazer desencadear o saber, propriamente dito, pois, é por meio de um processo de ensino que vise à liberdade intelectual e política do discente que as informações ganham conotações do conhecimento, enquanto elemento que emerge de uma prática reflexiva, crítica, ou seja, de uma análise acurada da informação.

A sociedade vaticinada como a arena do conhecimento exige senso crítico por parte do sujeito contemporâneo, assim este deve ser capaz de transformar a informação em conhecimento interveniente no meio social e, neste cenário a instituição escolar torna-se um espaço imprescindível para incitar e possibilitar reflexões. Ou seja, “[...] no mundo das novas tecnologias da comunicação e informação, a escola continua cumprindo funções que não são providas por nenhuma outra instância” (LIBÂNEO, 2001, p.172). Apesar de que algumas práticas escolares atualmente ainda possam ser definidas como oxidadas, Sibilia (2012) assinala que a escola ainda permanece como lócus socialmente legitimada de construção de conhecimento e aprendizagem. Deste modo, cabe aqui dar ênfase, mais uma vez, à Libâneo, pois o autor esclarece que "[...] o que está errado com a educação não é possível ser corrigido pela tecnologia" (LIBÂNEO, 2001, p.20). Isso significa que a rede tecnológica não pode ser encarada como a panaceia da educação, mas como um instrumento que, aliado a uma prática cotidianamente reflexiva, pode vir a contribuir como remédio de desoxidação. Além do mais, as informações veiculadas por meio da cultura midiática reclamam, antes de tudo, outras ideias, conceitos, representações sem esquecer, como diria Freire (2001), da necessidade do debate e do diálogo para a mudança.

Nesse caminho, a partir da compreensão de educação em um prisma dialógico, a comunicação parece ser uma condição indispensável para a construção dos processos de ensino e de aprendizagem, visto que a educação, enquanto prática social, se materializa em meio às relações sociais (LIBÂNEO, 2011). Conforme postula Freire (1992, p. 43), o "[...] diálogo é o encontro amoroso dos homens que, mediatizados pelo mundo, o pronunciam, isto é, o transformam, e, transformando-o, o humanizam para a humanização de todos". Logo, é possível perceber que, em interface com paradigma comunicacional, as TIC's na contemporaneidade adquirirem a nuance de um recurso propício para a materialização desse processo dialógico na arena escolar. 
Haja vista que na contemporaneidade novos corpos e subjetividades, bem diferentes daqueles de outrora, se assentam nos espaços escolares (SIBILIA, 2012), seria conveniente à escola buscar envolver os sujeitos contemporâneos com os mais diferentes artifícios tecnológicos, pois os alunos contemporâneos são "homo zappiens" (VEEN; VRAKKING, 2009) e já nascem inseridos dentro dessa nova configuração dialogal, que pode vir a parecer bastante estranha para aqueles que ainda insistem em se prender aos grilhões da modernidade. Pensar na inserção de alguns instrumentos tecnológicos em sala de aula, atendendo não apenas um interesse exclusivamente pedagógico, mas aos interesses dos nativos digitais, parece ser o tipo de educação coerente com essas novas gerações. Portanto, é fundamental para o entendimento da nova conjuntura civilizatória, reclamar uma formação escolar que possibilite os alunos a atuarem criativamente na arena da cultura midiática. Nesta perspectiva, cabe tanto ao professor quanto a escola fazer uso dos instrumentos tecnológicos a serviço dos processos de ensino e de aprendizagem, mostrando que esses recursos podem ter outros significados além da função de lazer, diversão ou distração.

E, assim, vem à tona a necessária formação contínua do professor, a qual exige planejamento, recursos tecnológicos e mediadores especializados, visando favorecer, com esteio em um prisma crítico, construtivo e autoral, a aproximação do docente com a cultura comunicacional e com os alunos contemporâneos que apresentam outros corpos e subjetividades, como bem rememora Sibilia (2012).

A escola, portanto, precisa materializar o investimento necessário no tocante a questão estrutural e tecnológica, já que ainda busca resguardar-se em sua tarefa de ensinagem. E, entretanto, é cediço que as escolas e professores não podem permanecer alheios a instância do campo tecnológico ou, ainda, insistirem na luta contra esses aparelhos, mas, ao contrário, devem, de preferência, incorporá-los à prática pedagógica e colocá-los a serviço da promoção do protagonismo estudantil e da concretização de uma cultura pedagógica em comunhão com o contexto contemporâneo. Nessa estrutura, impende retomar a indagação inicial: as tecnologias móveis são aliadas ou inimigas dos processos de ensino e de aprendizagem na escola atual?

As tecnologias de comunicação ganham os mais variados moldes na contemporaneidade e, cada vez mais, se renovam e adquirem têmpera criativa, opulenta e apresentam constantes novidades. Por isso, buscando dar conta da expansão das possibilidades do universo tecnológico, a Organização das Nações Unidas para a Educação, Ciência e Cultura - UNESCO (2013) lançou um documento no qual estão 
elencadas diretrizes de políticas para a aprendizagem móvel. A aludida organização de diretrizes visa estabelecer planos de ação. Logo, é coerente realçar a importância da elaboração de um instrumento dessa natureza, especialmente para o contexto educacional, que deve buscar se atualizar a todo o momento.

No rastro da questão ora discutida, convém deslindar o entendimento do conceito de mobilidade. Assim, conforme a UNESCO, a ideia de aprendizagem móvel se assenta no "[...] uso de tecnologias móveis, isoladamente ou em combinação com outras tecnologias de informação e comunicação (TIC), a fim de permitir a aprendizagem a qualquer hora e em qualquer lugar" (UNESCO, 2013, p.8). Classificamse como tecnologias móveis os smartphones, tablets, e-readers, dentre outros. No entanto, a instituição supracitada, dá destaque aos telefones celulares com acesso à internet, pois é crescente o número de indivíduos com acesso a este tipo de tecnologia, onde o grande diferencial está no fato de que cada um é proprietário de seu aparelho e tem controle de acesso.

Convém, nessa perspectiva, dar relevo que os alunos na contemporaneidade, cada vez mais, são possuidores dos mecanismos digitais e portáteis, visto que se torna comum nas salas de aula, seja na rede pública ou privada, uma realidade de relação imbricada que se tem construído entre os estudantes e este tipo de tecnologia. Talvez seja justamente nesse fato que resida o grande desafio da escola, isto é, faz-se necessário averiguar qual o espaço das tecnologias móveis na prática pedagógica corporificada nas salas de aula. Afinal, os aludidos instrumentos não são inimigos, mas podem ser aliados na concretização da formação dos sujeitos contemporâneos, pois despertam o interesse e a curiosidade dos alunos de mais variadas formas. Neste sentido, a UNESCO, por meio de suas diretrizes, lança a constatação de que na atualidade a "[...] aprendizagem pode ocorrer de várias formas: as pessoas podem usar aparelhos móveis para acessar recursos educacionais, conectar-se a outras pessoas ou criar conteúdos, dentro ou fora da sala de aula" (UNESCO, 2013, p.8). Ou seja, pensar em uma aprendizagem nessa perspectiva significa transformar primordialmente a ótica a respeito dos processos de ensino e de aprendizagem, haja vista que aprender deve ser o resultado de percurso e que, na atualidade, se distancia do uso exclusivo do giz, da lousa, do caderno e do lápis.

No entanto, os professores, ainda, demonstram resistência relacionada ao uso de novas tecnologias. Em contrapartida, verifica-se que é esperado que esses profissionais apresentem insegurança diante da nova tessitura tecnológica que se edifica, afinal são imigrantes digitais em sua maior parte. Porém, enquanto isso, os 
alunos vão estreitando cada vez mais sua relação com a internet e com a tecnologia porque exercem essas práticas com devoção cotidiana, o tempo todo, porque querem e porque isso lhes agrada (SIBILIA, 2012). Por isso, como assinala Nóvoa (2009, p. 65): “[...] hoje, talvez mais do que nunca, impõe-se reabilitar os modelos da 'diversificação pedagógica' como referência para uma escola centrada na aprendizagem”. Então, o que está posto é a necessidade de se repensar e ressignificar corpos e subjetividades por meio da educação, visando compreendê-los em seus desdobramentos no contexto atual e, assim, a suplantação do emaranhado de implicações e desafios decorrentes dos avanços tecnológicos para a prática docente e para a escola enquanto instituição de ensino.

\section{PERCURSO METODOLÓGICO}

Partindo do pressuposto que o ato de pesquisar é essencialmente um compromisso político, ético, emancipatório à medida que faz eclodir a ação comprometida com a mudança peremptória da sociedade, foi oportuno adotar-se nesse processo investigativo a abordagem qualitativa. Assim, executou-se uma pesquisa de campo, "[...] genericamente chamada, também, por alguns, pesquisa de cunho etnográfico, fenomenológico, construtivista, etc.” (CHIZZOTTI, 2003, p.223). A referida pesquisa a partir dos critérios, foram eles: professores com atuação na educação, ensino fundamental, mas especificamente do $6^{\circ}$ ao $9^{\circ}$ ano e com mais de dez anos de experiência no magistério, envolveu 6 professores do município de Iguatu/CE, os quais foram denominados de professores A, B, C, D e E.

Deste modo, utilizou-se semiestruturada e reflexiva visando colher os dados. Nesta toada, Triviños (2012) sustenta que a entrevista semiestruturada inicia-se a partir de pontos básicos correlatos a investigação e que, posterior, possibilita alargar a seara de interrogativas, produto de novas hipóteses que vem a lume à proporção que se colhem as respostas do entrevistado. Portanto, explorou-se a entrevista semiestruturada por oferecer ao depoente liberdade e espontaneidade, elementos que enriqueceram a investigação.

As questões que nortearam a entrevista se referiram à utilização das tecnologias móveis em sala de aula como recurso pedagógico e a qualificação profissional do docente para esse processo de inserção, de forma qualitativa, dos mecanismos tecnológicos nos processos de ensino e de aprendizagem. 
A partir do exposto, explanação do percurso metodológico adotado no desenvolvimento da pesquisa, o presente texto irá, doravante, apresentar os dados colhidos fundamentando-os a partir das contribuições dos autores que fortaleceram a discussão e, como ponto cabeiro, a discussão será concluída com a apresentação das ideias finais.

\section{RESULTADOS E DISCUSSÃO: DIALOGANDO COM OS SUJEITOS DA PESQUISA}

\section{O professor no contexto da mobilidade tecnológica: tecnologias móveis, recurso pedagógico?}

Uma das indagações perseguidas por esta pesquisa foi à investigação a respeito da utilização, por parte do professor, das tecnologias móveis em sala de aula como recurso pedagógico, pois se entende como recurso pedagógico os instrumentos que servem de meio para o favorecimento dos processos de ensino e de aprendizagem. Desta feita, traz-se à baila que, no cenário atual, as TIC's, as tecnologias móveis, se encaixam nesses artefatos, haja vista que sua utilização pretende atingir significativamente aos sujeitos contemporâneos. Todavia, apesar de ainda existirem dificuldades no que tange à implantação da estrutura devidamente amparada pelo uso da tecnologia, o desafio atual se assenta na capacitação da mão de obra docente para a utilização desses recursos. Tal reflexão se confirma no pensamento de Tardif ao enfatizar que: “[...] oferece-se às escolas e aos professores cursos já pré-fabricados, manuais, computadores, ferramentas pedagógicas com abordagens, estratégias e objetivos de aprendizagem" (TARDIF, 2013, p.565).

Fica claro, portanto, que a formação oportunizada ao docente, consonante as contribuições do autor, não se funda em um processo de formação a partir das dificuldades específicas do seu cotidiano, todavia, apresentam propostas cabais que culminarão na aplicação mecânica por parte do docente, embora a escola seja constituída por arenas diferenciadas, espaços e tempos. Em contrapartida, Libâneo (2005) entende que a natureza do pedagógico se resguarda na intencionalidade, ou seja, o ato educativo é que uma atividade humana intencional. A intencionalidade se firma no conhecimento que os docentes possuem acerca dos recursos que pretendem utilizar em suas aulas. 
São muitas as tecnologias com as quais os professores se relacionam e possuem propriedade. Algumas delas são os computadores, os recursos de áudio, vídeo e até a própria internet como fonte de pesquisa. Apesar disso, as tecnologias móveis, especialmente os smartphones e tablets, ainda se apresentam bastante desafiadoras no contexto escolar. Por isso, conforme destaca Sibilia (2012, p.173), a instituição escolar ainda permanece com práticas de "[...] proibir os alunos de entrar nos edifícios com suas próprias câmeras e demais dispositivos característicos da sociedade de controle". Isso traz implicações às experiências educativas, haja vista que "[...] as escolas têm boas condições para fornecer orientação sobre os usos adequados e produtivos dos aparelhos móveis e, em muitos casos, é improvável que os estudantes recebam essa orientação em outros lugares" (UNESCO, 2013, p.39).

Fica patente, portanto, que para as tecnologias móveis possam ser utilizadas como recurso pedagógico o professor precisa compreendê-las, mas, principalmente, assegurar-se de forma pedagógica de seu uso, pois, somente assim conseguirá incluir esses instrumentos em uma ação intencionalmente planejada que tenha a aprendizagem como finalidade, pois como postula Sibilia (2012, p.182), "[...] nem os computadores, nem a internet, nem os telefones celulares são recursos neutros, como se costuma dizer, cuja eficácia dependeria da utilização que lhes é dada". A partir disso, verifica-se que o espontaneísmo em relação ao uso da aparelhagem tecnológica nas práticas educativas, deixa evidente que o professor não foi adequadamente formado a respeito de como integrá-los efetivamente na sua prática.

Logo, é profícuo assinalar que a inclusão das tecnologias móveis na prática pedagógica só poderá ser autêntica quando precedida por um processo de formação para o docente que o possibilite laborar no contexto da mobilidade tecnológica de forma segura, crítica e autônoma. Ou seja, a inserção dos aludidos mecanismos no contexto escolar reclama, a priori, um processo de formação do docente interligado a aparelhagem tecnológica. Por isso, é necessário a promoção do desenvolvimento qualitativo do docente a partir de uma cultura de formação onde tecnologia e prática pedagógica se relacionem de modo horizontalizado.

O professor não deve abdicar de atuar em simbiose com a cultura das tecnologias, pois por meio dela poderá instaurar um processo dialógico pleno consigo mesmo, com o outro e com os mais variados contextos contemporâneos. Assumir a tecnologia possibilitará ao professor descortinar novos saberes, novas práticas e difundir o conhecimento utilizando-se dos instrumentos atrativos aos alunos dos dias de hoje. 
Entretanto, verifica-se que um fator importante é o número de professores que assinalam não se sentirem preparados para utilizar os aludidos aparatos tecnológicos com enfoque pedagógico. Tal assertiva pode ser entendida na declaração abaixo:

\begin{abstract}
Sinceramente, não me sinto preparada, nem vivencio um processo de formação que me oportunize os conhecimentos necessários para utilizar os recursos tecnológicos móveis na minha prática pedagógica. Porém, tenho muita vontade de participar de cursos, formação nessa área e vencer muitos medos em relação à tecnologia (Professora $\mathrm{B}$ ).
\end{abstract}

Aproxima-se da supracitada declaração o depoimento abaixo:

\begin{abstract}
Não estou, de fato, preparada e nem percebo por parte da escola na qual trabalho um incentivo, em relação à formação, para que eu possa superar os medos e, então, utilizar os recursos tecnológicos móveis na minha prática docente. O que percebo, por parte da escola, são discursos, como: pessoal, a escola dispõe de muitos recursos tecnológicos, vamos procurar utilizá-los, porém, não trabalha conosco o como, para quê e quando utilizá-los. Não vou mentir, tenho muitas dúvidas em relação a esse assunto (Professor C).
\end{abstract}

Apreende-se, então, que os professores necessitam de um processo de formação que contribua para o florescimento de uma prática pedagógica coadunada a mobilidade tecnológica e com as demais tecnologias, visto que o titubeio por parte dos professores é resultado, entre outros fatores, da formação do docente insuficiente e, muitas vezes, ainda excessivamente tradicional. Esse tipo de formação não robustece a autonomia do professor para assentar-se no contexto da mobilidade tecnológica de forma segura e pedagógica. No rastro dessa questão, Libâneo (2002, p. 35) assinala que "[...] muitos professores sentem necessidade de mudanças no seu trabalho e sabem que, para introduzi-las no seu trabalho, dependem e melhor formação pedagógico-didática". Nesta perspectiva, para o desdenhamento de tal quadro, faz-se necessário um liame entre os contextos de formação dos professores e o campo das tecnológicas móveis. Tal prática contribuirá para a suplantação dos elementos patentes nas afirmações abaixo:

Acho uma perda de tempo eu tentar trabalhar usando instrumentos da tecnologia, pois é uma situação difícil prá mim que não tenho formação para isso, e muitas vezes não sei nem manusear esses recursos. Assim como os mesmos não fazem parte do cotidiano da maioria dos alunos. Porém, eu procuro outros meios, recursos, visando fazer diferente, inovar, levar algo novo para a sala de aula no tocante a recursos pedagógicos (Professor A). 
$\mathrm{Eu}$ reconheço que tenho muita resistência quanto ao uso de instrumentos ligados a tecnologia na prática pedagógica, e as formações das quais eu participo não me tão subsídio para eu passar a utilizá-los na sala de aula. Pois isso, não mim sinto preparada e, assim, acabo não usando os mesmos, embora os alunos me instiguem a utilizá-los (Professor D).

A suplantação da aludida cisão exige, antes de tudo, um docente seguro, sujeito de um processo de formação coerente e interligada às transformações tecnológicas, para que, assim, o professor possa fazer o aproveitamento positivo das tecnologias móveis na prática pedagógica. Para tanto, é importante que os professores contem com um ambiente formativo que facilite o acesso ao conhecimento e aos recursos tecnológicos, isto é, formação e equipamentos tecnológicos móveis ou não a serviço da materialização dos processos de ensino-aprendizagem. É legítimo, contudo, dar ênfase que as redes sociais digitais, presentes no cotidiano dos sujeitos contemporâneos, são outra oportunidade de mediação e interligação do processo educativo ao contexto da mobilidade tecnológica. Tais redes podem oportunizar a integração do professor as novas possibilidades de aprendizagem, produção do conhecimento, ou seja, a mobilidade docente, produto de uma prática efetiva do professor na arena da pluralidade tecnológica.

Em suma, os professores podem se beneficiar do patrimônio tecnológico aproximando-se de todo esse instrumental, haja vista que o crescimento vertiginoso da tecnologia amplia os aparatos técnicos que contribuem para maior visibilidade, difusão do conhecimento e favorece, sem dúvida, a corporificação de um processo dialógico, com moldes contemporâneos, é claro. Enfim, sua relação com os processos de ensino e de aprendizagem, reclama, antes de tudo, a suplantação de estorvos, como os descritos nas assertivas abaixo:

Na escola na qual eu trabalho são poucos os recursos tecnológicos disponíveis e, porém, utilizados. Geralmente, resume-se ao uso do projetor multimídia e do notebook para passar filmes para os alunos, e raramente. Por isso, não considero que utilizo os recursos tecnológicos móveis na minha prática pedagógica, assim como não me sinto preparada. Seria bom que todos os professores utilizassem esses recursos em sala de aula. Pois eles enriquecem as aulas, os alunos ficam mais motivados, mas nem todas as escolas dispõem desses recursos e, ainda, proíbe o uso de alguns aparelhos por parte dos alunos. E o pior que nós professores não temos uma formação que nos ajude a utilizá-los de forma adequada (Professora E). 
Com base no que foi exposto, mais precisamente as informações obtidas durante as entrevistas, conclui-se que o processo investigativo materializado permite dar relevo a duas categorias, são elas: a não utilização das tecnologias móveis como recurso pedagógico nas salas de aula e a qualificação do docente insuficiente para uma autêntica atuação do professor no contexto da mobilidade tecnológica. Tal compreensão possibilita assinalar, por último, que o silêncio no que concerne a um diálogo dos professores com os aparatos tecnológicos na prática pedagógica permeia o âmago de muitas escolas brasileiras.

É importante que cada escola concretize um processo de formação contínua que contribua com o professor no sentido de alavancar mudanças no campo das concepções, convicções teóricas em relação à arena da tecnologia e a sua inserção na prática pedagógica, pois, o quadro apontado pelos professores, em relação ao uso dos aparatos tecnológicos como recursos pedagógicos, só poderá ser sobrepujado à medida que o docente vivenciar um processo de formação sistemático e consonante as necessidades provenientes do exercício docente no contexto da contemporaneidade. Uma vez traçado e vivenciado com os professores, o aludido processo de formação deve ser alvo de constante avaliação, isto é, contar com momentos de revisitação das práticas pedagógicas, dos conteúdos e práticas que integra o referido processo, visando corresponder as principais demandas do cotidiano escolar, entre elas, a necessária articulação do processo educativo com a arena das mutações tecnológicas. Sibilia (2012) afirma com veemência que tudo na sociedade contemporânea é efêmero. Por isso, em suma, para aferir a eficácia do processo formativo contínuo do docente, são necessários mecanismos de avaliação capazes de acompanhar suas implicações na reconstrução das práticas pedagógicas, por consequência, dos processos de ensino e de aprendizagem que sofrem reconfiguração a todo tempo.

A escola, portanto, constitui-se como o lugar, por excelência, para a concretização do processo de formação contínua do docente. Sendo assim, é plausível apontar que o referido processo deve ser fundado na perspectiva dialógica, na troca de experiências e na delineação de atividades direcionadas pelo eixo da dinamicidade e que visem dar sentido ao ensino e a aprendizagem, em interface ao contexto da conectividade, interatividade, em outras palavras, diante da cultura da informação, da comunicação e da mobilidade. 


\section{CONCLUSÕES}

Diante das assertivas apresentadas, há indícios de que não existe, ao menos de modo patente, a utilização das tecnologias móveis em sala de aula como recurso pedagógico. Tal fato se explica, com esteio na segunda questão, que sustentou a investigação: a qualificação do professor se apresenta insuficiente e não o torna seguro para estabelecer uma relação dialógica entre sua prática pedagógica e a arena das tecnologias móveis. O que traz à tona a indagação alçada neste corpo teórico: as tecnologias móveis são aliadas ou inimigas dos processos de ensino e de aprendizagem? No rastro dessa questão sedimenta-se a convicção de que somente por meio de uma formação docente qualitativa será possível cercear esse mal-estar docente em interface a utilização dos recursos tecnológicos móveis em sala de aula.

O contexto contemporâneo, no entanto, marcado pelas novas tecnologias, está a exigir dos professores novas práticas diante do conhecimento, objetivando preparar as novas gerações para laborar criticamente em interface a essa arena, pois, no referido contexto, milhares de pessoas tornam-se usuárias frenéticas e assíduas da aparelhagem tecnológica, com contundente familiaridade e interatividade. Cada vez mais, as novas gerações correspondem com facilidade aos diversos estímulos provenientes dessa seara, assim, executam paralelamente diferentes atividades, como: estudar, trabalhar, comunicar-se, jogar, entre outras, isto é, transitam com agilidade, desenvoltura nesse ambiente. Assim como manifestam curiosidade, inquietações latentes, resiliência para adaptar-se a esse campo abalizado por frequentes inovações. Por isso, é necessário estabelecer uma relação entre o universo escolar e a arena das tecnologias.

Entretanto, a inserção das inusitadas gerações no campo tecnológico reclama, antes de tudo, uma formação que desperte o sujeito para um uso consciente das novas tecnologias, sobretudo dos aparelhos tecnológicos móveis, fazendo, então, com que os referidos recursos estejam a servir o homem, e não ao contrário, o homem escravo dos mesmos. Deste modo, o professor ao usar as mais variadas tecnologias em sala de aula, precisa estar cônscio dos objetivos que almeja com o uso dessas ferramentas, pois, inovar as técnicas não assegura, necessariamente, a eficiência nos processos de ensinoaprendizagem. Cabe, contudo, ao professor revisitar suas concepções a respeito da educação, visando deslindar novas facetas educativas, comprometidas com a transformação baseada nas possibilidades decorrentes da práxis docente. 
Trata-se, portanto, de materializar uma formação que oportunize as novas gerações autonomia e competências, como: envergadura argumentativa, flexibilidade, visão crítica diante dos fatos, pensamento autônomo. Portanto, a mobilidade torna isso possível, pois exige dinamismo de quem a utiliza. Assim, faz-se necessário formar um contingente de sujeitos emancipados e não simples indivíduos que vivem sob a batuta de uma ideologia de pessoas que apenas executam, mas que não refletem e nem pensam sobre outras óticas e modos de fazer e realizar ações enquanto sujeitos sociais.

Por último, enquanto se discute a cisão da relação das tecnologias móveis nos processos de ensino e de aprendizagem, enquanto elemento que contribuirá para a mobilidade docente por meio da cultura midiática, os discentes tornam-se, cada vez mais, usuários assíduos da aparelhagem tecnológica móvel que permite acessibilidade ao mundo da informação e interatividade. Nesse diapasão, a intenção desta pesquisa foi tornar a discussão mais aguerrida a respeito da necessária instauração de uma relação harmônica entre o processo educativo e as tecnologias móveis, o que exige, antes de tudo, um professor seguro e consciente que os aparatos tecnológicos podem estar a serviço da promoção do (auto)conhecimento.

Visando concluir, segue alguns apontamentos que, via de regra, poderá contribuir com as escolas no que concerne a necessária ruptura de estorvos que obstaculizam a inserção das tecnologias móveis na prática pedagógica dos professores:

- Promover, junto aos professores, atividades formativas, objetivando abordar a dimensão do uso das tecnologias nos processos de ensino e de aprendizagem;

- Motivar maior inserção da aparelhagem tecnológica, incluindo tablets e smartphones, como recursos pedagógicos no contexto escolar;

- Desenvolver projetos e trabalhos com âncora na coletividade, visando colocar a população docente-discente em contato com diferentes aparatos tecnológicos móveis e com seus interesses frente ao ensino-aprendizagem.

Com arrimo nesses apontamentos finais, procurou-se enfatizar a importância dos professores em meio aos desdobramentos da tecnologia no cenário educacional, mas, também, destacar a relevância da participação e contribuição da equipe gestora, diretiva, da comunidade escolar e do apoio governamental em interface aos desafios que a contemporaneidade propõe a escola diante das mudanças tecnológicas. Assim, faz-se necessário uma parceria mais viva e eficaz entre escola, professores e outros segmentos 
escolares e políticos, buscando concretizar o protagonismo e mobilidade docente diante das tecnologias móveis, bem como a formação de sujeitos capazes, dinâmicos, reflexivos e ativos em seu meio social. Afinal, a educação é para isso. A educação é para transformar.

\section{MOBILE TECHNOLOGIES IN PROCESS OF TEACHING AND LEARNING: TEACHING MOBILITY?}

ABSTRACT: The article is a survey of basic education teachers in the municipality of Iguatu/CE and aimed to verify if teachers use mobile technology in the classroom as an educational resource, as well as investigate to what extent the professional qualifications of these professionals drives an authentic, autonomous teaching action before the harvest of mobile technologies. The subjects are teachers who work in elementary school. Methodologically, constitutes in a field research, with retaining the qualitative approach, aiming to enhance the school in contemporary times is addressed by changes brought to the company by the technological revolution, especially the proliferation of mobile technologies, which are driving changes in processes teaching and learning. We used semi structured and reflective interview as a technique for data collection. They have as the theoretical studies of Alarcão (2001), Freire (1987, 1992, 2001), Libâneo (2001, 2002, 2005, 2011), Nóvoa (2009), Tardif (2001) UNESCO (2013), Veen and Vrakking (2009). The results of the research showed that teachers, for the most part, do not use the apparatus of mobile technologies in pedagogical practice, and point to the picture of insufficient professional qualification for a teaching practice in the context of safe and educationally effectively technologies. However, this split ends, so in need of a continuous training process that deepens also in reality and knowledge that teachers have. As regard as pillars the changes that the current social context has experienced, among which we highlight the technological changes that proliferate dramatically.

KEYWORDS: Mobile technologies. Teaching and learning. Teacher training.

\section{REFERENCIAS}

\section{ALARCÃO, I. A escola reflexiva. In: ALARCÃO, I. (Org.). Escola reflexiva e nova} racionalidade. Porto Alegre: Artmed, 2001. p.15-30.

CHIZZOTTI. A. A pesquisa qualitativa em ciências humanas e sociais: evolução e desafios. Revista Portuguesa de Educação, Braga, PT, v.16, n.2, p.221-236, 2003. Disponível em: <http://200.17.83.38/portal/upload/com_arquivo/1350495029.pdf>. Acesso em: 12 jun. 2015.

FREIRE, P. Educação como prática da liberdade. 25.ed. Rio de Janeiro: Paz e Terra, 2001.

Comunicação e Extensão. Trad. de Rosisca Darcy de Oliveira. 10.ed. Rio de Janeiro: Paz e Terra, 1992. 
Pedagogia do Oprimido. 17. ed. Rio de Janeiro: Paz e Terra, 1987.

LIBÂNEO, J. C. Ainda as perguntas: que é pedagogia, quem é o pedagogo, o que deve ser o curso de Pedagogia. In: PIMENTA, S. G. (Org.). Pedagogia e pedagogos: caminhos e perspectivas. 3.ed. São Paulo: Cortez, 2011. p.63-100.

Pedagogia e pedagogos, para quê?. São Paulo: Cortez, 2005.

Produção de saberes na escola: suspeitas e apostas. In: CANDAU, V. M.

(Org.). Didática, currículo e saberes escolares. 2.ed. Rio de Janeiro: DP\&A, 2002. p.11-45.

Pedagogia e pedagogos: inquietações e buscas. Educar, Curitiba, n. 17, p.153176, 2001. Disponível em: <http://www.scielo.br/pdf/er/n17/n17a12.pdf>. Acesso em: 22 de set. 2015

NÓVOA, A. Professores: imagens do futuro presente. Lisboa: EDUCA, 2009.

SIBILIA, P. Redes ou paredes: a escola em tempos de dispersão. Rio de Janeiro: Contraponto, 2012.

TARDIF, M. Profissionalização do ensino passados trinta anos: dois passos para a frente, três para trás. Educação e Sociedade, Campinas, v.34, n.123, p.551-571, abr.jun. 2013. Disponível em: 〈http://www.scielo.br/pdf/es/v34n123/13.pdf>. Acesso em: 15 set. 2015.

TRIVIÑOS, A. N. S. Introdução à pesquisa em ciências sociais: a pesquisa qualitativa em educação. 21. reimpr. São Paulo: Atlas, 2012.

UNESCO. Policy guidelines for mobile learning. 2013. Disponível em: <http://unesdoc.unesco.org/images/0021/002196/219641E.pdf >. Acesso em: 20 mar. 2016.

VEEN, W.; VRAKKING, B. Homo Zappiens: educando na era digital. Tradução Vinícius Figueiredo. Porto Alegre: Artmed, 2009. 